\title{
Technical aspects of endoscopic ultrasound (EUS)-guided sampling in gastroenterology: European Society of Gastrointestinal Endoscopy (ESGE) Technical Guideline - March 2017
}

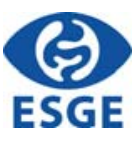

Authors

Marcin Polkowski ${ }^{1,2}$, Christian Jenssen ${ }^{3}$, Philip Kaye ${ }^{4}$, Silvia Carrara ${ }^{5}$, Pierre Deprez ${ }^{6}$, Angels Gines ${ }^{7}$, Gloria FernándezEsparrach $^{7}$, Pierre Eisendrath ${ }^{8}$, Guruprasad P. Aithal ${ }^{4}$, Paolo Arcidiacono ${ }^{9}$, Marc Barthet ${ }^{10}$, Pedro Bastos ${ }^{11}$, Adele Fornelli ${ }^{12}$, Bertrand Napoleon ${ }^{13}$, Julio Iglesias-Garcia ${ }^{14}$, Andrada Seicean ${ }^{15}$, Alberto Larghi ${ }^{16}$, Cesare Hassan ${ }^{16}$, Jeanin E. van Hooft ${ }^{17}$, Jean-Marc Dumonceau ${ }^{18}$

\section{Institutions}

1 Department of Gastroenterology, Hepatology, and Oncology, Medical Centre for Postgraduate Education, Warsaw, Poland

2 Department of Gastroenterological Oncology, The M. Skłodowska-Curie Memorial Cancer Centre, Warsaw, Poland

3 Department of Internal Medicine, Krankenhaus Märkisch Oderland Strausberg/Wriezen, Academic Teaching Hospital of the Medical University of Brandenburg, Germany

4 Nottingham Digestive Diseases Centre, NIHR Nottingham Biomedical Research Centre, Nottingham University Hospitals NHS Trust and University of Nottingham, UK

5 Digestive Endoscopy Unit, Division of Gastroenterology, Humanitas Research Hospital, Rozzano, Italy

6 Cliniques Universitaires St-Luc, Université Catholique de Louvain, Brussels, Belgium

7 Endoscopy Unit, Department of Gastroenterology, ICMDM, IDIBAPS, CIBEREHD, Hospital Clínic, Barcelona, Spain

8 Department of Gastroenterology, Hepatopancreatology, and Digestive Oncology, Université Libre de Bruxelles, Hôpital Erasme \& Hôpital Saint-Pierre, Brussels, Belgium

9 Pancreato-Biliary Endoscopy and Endosonography Division, San Raffaele University, Milan, Italy

10 Service de Gastroentérologie, Hôpital NORD AP-HM, Aix-Marseille-Université, Marseille, France

11 Gastroenterology Department Instituto Português de Oncologia do Porto, Porto, Portugal

12 Anatomic Pathology Unit, AUSL of Bologna, Maggiore Hospital, Bologna, Italy

13 Department of Gastroenterology, Ramsay Générale de Santé, Private Hospital Jean Mermoz, Lyon, France
14 Gastroenterology Department, University Hospital of Santiago de Compostela, Santiago de Compostela, Spain

15 Regional Institute of Gastroenterology and Hepatology, Iuliu Hatieganu University of Medicine and Pharmacy, Cluj-Napoca, Romania

16 Digestive Endoscopy Unit, Catholic University, Rome, Italy

17 Department of Gastroenterology and Hepatology, Academic Medical Center, Amsterdam, The Netherlands

18 Gedyt Endoscopy Center, Buenos Aires, Argentina

Bibliography

DOI https://doi.org/10.1055/s-0043-119219

Published online: 12.9.2017 | Endoscopy 2017; 49: 989-1006

(c) Georg Thieme Verlag KG Stuttgart · New York

ISSN 0013-726X

Corresponding author

Marcin Polkowski, MD, Department of Gastroenterological Oncology, M. Sklodowska-Curie Memorial Cancer Center and Institute of Oncology, Roentgena 5, 02-781 Warsaw, Poland

Fax: +48-22-5463035

mp.polkowski@gmail.com

\# Appendix e1, e2 and Supplementary material Table s1 -s14 Online content viewable at:

https://doi.org/10.1055/s-0043-119219 


\section{RECOMMENDATIONS}

For routine EUS-guided sampling of solid masses and lymph nodes (LNs) ESGE recommends 25G or 22G needles (high quality evidence, strong recommendation); fine needle aspiration (FNA) and fine needle biopsy (FNB) needles are equally recommended (high quality evidence, strong recommendation).

When the primary aim of sampling is to obtain a core tissue specimen, ESGE suggests using 19G FNA or FNB needles or 22G FNB needles (low quality evidence, weak recommendation).

ESGE recommends using 10-mL syringe suction for EUSguided sampling of solid masses and LNs with $25 \mathrm{G}$ or $22 \mathrm{G}$ FNA needles (high quality evidence, strong recommendation) and other types of needles (low quality evidence, weak recommendation).

ESGE suggests neutralizing residual negative pressure in the needle before withdrawing the needle from the target lesion (moderate quality evidence, weak recommendation). ESGE does not recommend for or against using the needle stylet for EUS-guided sampling of solid masses and LNs with FNA needles (high quality evidence, strong recommendation) and suggests using the needle stylet for EUSguided sampling with FNB needles (low quality evidence, weak recommendation).

ESGE suggests fanning the needle throughout the lesion when sampling solid masses and LNs (moderate quality evidence, weak recommendation).
ESGE equally recommends EUS-guided sampling with or without on-site cytologic evaluation (moderate quality evidence, strong recommendation). When on-site cytologic evaluation is unavailable, ESGE suggests performance of three to four needle passes with an FNA needle or two to three passes with an FNB needle (low quality evidence, weak recommendation).

For diagnostic sampling of pancreatic cystic lesions without a solid component, ESGE suggests emptying the cyst with a single pass of a 22G or 19G needle (low quality evidence, weak recommendation). For pancreatic cystic lesions with a solid component, ESGE suggests sampling of the solid component using the same technique as in the case of other solid lesions (low quality evidence, weak recommendation).

ESGE does not recommend antibiotic prophylaxis for EUSguided sampling of solid masses or LNs (low quality evidence, strong recommendation), and suggests antibiotic prophylaxis with fluoroquinolones or beta-lactam antibiotics for EUS-guided sampling of cystic lesions (low quality evidence, weak recommendation).

ESGE suggests that evaluation of tissue obtained by EUSguided sampling should include histologic preparations (e.g., cell blocks and/or formalin-fixed and paraffinembedded tissue fragments) and should not be limited to smear cytology (low quality evidence, weak recommendation).

$\begin{array}{ll}\text { ABBREVIATIONS } \\ \text { CI } & \text { confidence interval } \\ \text { ESGE } & \text { European Society of Gastrointestinal Endoscopy } \\ \text { EUS } & \text { endoscopic ultrasound } \\ \text { FNA } & \text { fine needle aspiration } \\ \text { FNB } & \text { fine needle biopsy } \\ \text { G } & \text { gauge } \\ \text { GRADE } & \text { Grading of Recommendations Assessment, } \\ & \text { Development and Evaluation } \\ \text { LN } & \text { lymph node } \\ \text { RCT } & \text { randomized controlled trial } \\ \text { ROSE } & \text { rapid on-site cytologic evaluation }\end{array}$

This Guideline from the European Society of Gastrointestinal Endoscopy (ESGE) focuses on the technical aspects of endoscopic ultrasound (EUS)-guided sampling in gastroenterology, such as the choice of needle, the sampling technique, and specimen handling and processing. A separate Clinical Guideline addresses the indications, results, and clinical impact of EUS-guided sampling.

\section{Guideline focus}

This Guideline from the European Society of Gastrointestinal Endoscopy (ESGE) focuses on technical aspects of endoscopic ultrasonography (EUS)-guided sampling in gastroenterologythe choice of needle, sampling technique, and specimen handling and processing-and updates the previous guideline on these topics published in 2012 [1]. The target audience for this Guideline is endoscopists who perform EUS-guided sampling. Indications, results, and clinical impact of EUS-guided sampling are addressed in a separate clinical Guideline from ESGE [2].

\section{Guideline development process}

ESGE commissioned this Guideline and appointed a Guideline leader (J.M.D.) who invited the listed authors to participate in the project development. The key questions were prepared by the coordinating team (M.P., J.M.D.) and then approved by the other members. The coordinating team formulated key questions and assigned them to task force subgroups (Appendix e1 and Appendix e2, available online-only).

Each task force performed a systematic literature search to prepare evidence-based and well-balanced statements on their assigned key questions. The literature search was performed in Medline through PubMed to identify new publications since 
February 2011, focusing on meta-analyses and prospective studies, particularly randomized controlled trials (RCTs). Retrospective analyses and pilot studies were also included if they addressed topics not covered in the prospective studies. Each task force proposed statements on their assigned key questions which were discussed during a meeting in September 2016. The Grading of Recommendations Assessment, Development and Evaluation (GRADE) system was adopted to define the quality of evidence and strength of recommendation [3-7].

The significance of the four levels of evidence quality is explained in $>$ Table1 [4]. The strength of a recommendation, either strong or weak, was defined according to GRADE guidelines as the extent to which one can be confident that the desirable effects of an intervention outweigh its undesirable effects [5]. The decision on the recommendation strength considers both the quality of evidence and the risks, benefits, and costs of the approach being recommended. A strong recommendation supports a decision that should apply to most patients most of the time; a weak recommendation means that the decision is more nuanced and some clinicians might not choose the recommended approach $[5,8]$.

Literature searches were re-run in March 2017. This timepoint should be the starting point in the search for new evidence for future updates to this Guideline. In April 2017 a draft prepared by M.P. was sent to all group members for review. The draft was also reviewed by two members of the ESGE Governing Board and sent for further comments to the ESGE National Societies and Individual Members. After agreement on a final version, the manuscript was submitted to the journal Endoscopy for publication. All authors agreed on the final revised version.

This Guideline will be considered for review in 2022, or sooner if new and relevant evidence becomes available. Any updates to the Guideline in the interim period will be noted on the ESGE website: http://www.esge.com/ esge-guidelines.html.

\section{Outcomes used in studies on EUS-guided sampling techniques}

Technical aspects of EUS-guided sampling have been evaluated in more than 40 RCTs [9-49], several meta-analyses [50-60], and numerous studies with lower quality evidence levels. These studies used a variety of outcomes that can be broadly divided into five categories: (i) diagnostic accuracy; (ii) safety; (iii) sample adequacy and quality; (iv) technical performance of the needle; and ( $v$ ) costs ( $\triangleright$ Table 2 ). Diagnostic accuracy is considered a surrogate outcome for patient-important outcomes and hence the most important outcome in studies evaluating diagnostic tests $[55,61]$. Despite this fact, many studies did not evaluate accuracy and focused on outcomes related to sample adequacy and quality and to technical performance of the needle. These outcomes are inconsistently defined across the studies and their clinical significance is generally not well established. In addition, they are assessed using various nonvalidated scales and most likely subject to significant interobserver variability [62]. Adverse events are another patient-important outcome; however, none of the available RCTs was primarily designed and adequately powered to evaluate safety issues.

\section{Limitations of the available evidence}

Results of EUS-guided sampling may depend on numerous factors related to the target lesion, needle size and type, sampling technique, specimen handling and processing, and the endosonographer and pathologist. These factors are often interrelated and it is hardly possible to disentangle their relative effects in studies that look at them in isolation. In addition, the high number of involved factors makes it impossible to evaluate all of their potential combinations in $2 \times 2$ RCTs. Most RCTs focus on sampling technique and there is a paucity of studies evaluating various methods of specimen handling and processing. The same holds true for studies evaluating issues related to costs of the procedure.

- Table 1 Significance of the four levels of evidence quality according to Grading of Recommendations Assessment, Development and Evaluation (GRADE) guidelines [4].

\begin{tabular}{|c|c|c|}
\hline Quality level & Definition & Source of the evidence \\
\hline High & $\begin{array}{l}\text { We are very confident that the true effect lies close to that of } \\
\text { the estimate of the effect }\end{array}$ & $\begin{array}{l}\text { Randomized controlled trials without methodological } \\
\text { limitations. }\end{array}$ \\
\hline Moderate & $\begin{array}{l}\text { We are moderately confident in the effect estimate: The true } \\
\text { effect is likely to be close to the estimate of the effect, but } \\
\text { there is a possibility that it is substantially different }\end{array}$ & $\begin{array}{l}\text { Randomized controlled trials with serious methodological } \\
\text { limitations. }\end{array}$ \\
\hline Low & $\begin{array}{l}\text { Our confidence in the effect estimate is limited: The true } \\
\text { effect may be substantially different from the estimate of } \\
\text { the effect }\end{array}$ & \multirow{2}{*}{$\begin{array}{l}\text { Randomized controlled trials with very serious methodological } \\
\text { limitations and/or observational studies. }\end{array}$} \\
\hline Very low & $\begin{array}{l}\text { We have very little confidence in the effect estimate: The } \\
\text { true effect is likely to be substantially different from the } \\
\text { estimate of effect }\end{array}$ & \\
\hline
\end{tabular}


- Table 2 Outcomes evaluated in randomized controlled trials on techniques of endoscopic ultrasound (EUS)-guided sampling.

\begin{tabular}{|c|c|}
\hline Outcome groups & Specific outcomes \\
\hline Diagnostic accuracy & Sensitivity, specificity, accuracy for malignancy/neoplasia \\
\hline Safety & Adverse event rate and severity \\
\hline \multirow[t]{5}{*}{ Sample adequacy and quality } & Proportion of samples adequate for cytologic evaluation/histologic evaluation/diagnosis \\
\hline & Diagnostic yield of malignancy* \\
\hline & Number of needle passes: to establish diagnosis/to obtain an adequate or diagnostic sample \\
\hline & Sample cellularity/bloodiness/contamination with gastrointestinal tract cells \\
\hline & Proportion of core tissue procurement, length/width of the core tissue specimen \\
\hline \multirow[t]{3}{*}{ Needle technical performance } & Technical failure rate \\
\hline & Needle visibility/maneuverability \\
\hline & Ease-of-puncture/rate of difficult puncture \\
\hline Cost & Direct cost of the procedure, cost- effectiveness \\
\hline
\end{tabular}

Available RCTs evaluated relatively small patient samples and were underpowered to detect small but clinically relevant differences in evaluated outcomes. Only two parallel-group RCTs included more than 100 patients per group [14,47]. Only a few crossover RCTs evaluated more than 100 patients [20, 25, $39,41,44]$. While a difference in accuracy for malignancy of $10 \%$ seems clinically significant, the studies were often designed to exclude a much larger difference of $15 \%-25 \%$ between groups $[12,14,15,17,27,30,32,34,47]$. Most studies included exclusively or predominantly patients with solid pancreatic masses; evidence on EUS-guided sampling of other target lesions is limited. The pathologists who assessed the samples were blinded to the type of needle and sampling technique used; however, the endosonographer was not, and hence bias from this source cannot be excluded. Standard of reference was predominantly based on clinical and imaging follow-up, and verification by surgical pathology was available in only a minority of patients. Needles from two manufacturers were used in most of the discussed RCTs (Tables S1-S5 and S7S13, online-only in Supplementary material) and it is uncertain whether the results of these studies can be extrapolated to needles by other manufacturers. Finally, results from studies conducted at high volume centers by experts may not be generalizable to low volume centers and less experienced operators.

\section{Sampling of solid masses and lymph nodes}

\section{Choice of needle}

\section{RECOMMENDATION}

For routine EUS-guided sampling of solid masses and lymph nodes (LNs) ESGE recommends $25 \mathrm{G}$ or $22 \mathrm{G}$ needles (high quality evidence, strong recommendation); fine needle aspiration (FNA) and fine needle biopsy (FNB) needles are equally recommended (high quality evidence, strong recommendation).

When the primary aim of sampling is to obtain a core tissue specimen, ESGE suggests using 19G FNA or FNB needles or 22G FNB needles (low quality evidence, weak recommendation).

\section{Summary of evidence}

\section{Needle type}

New needle types primarily designed to procure samples with preserved tissue architecture, suitable for histologic evaluation, have been introduced in recent years. These devices, here collectively referred to as FNB needles, feature either a special geometry of the cutting tip or a side-slot (core trap) at the needle distal portion ( $>$ Table 3 ). Conventional needles without these refinements are here referred to as FNA needles. Needles with a side port (EZ-Shot 2/EZ-shot 3 with side port, Olympus) are considered to be FNA needles, because the nonbeveled side port is not designed to cut tissue [23].

Among the FNB needles, it is the reverse bevel needle (ProCore; Cook Medical) that has been evaluated most thoroughly. Evidence on other FNB needles, such as the fork-tip needle (SharkCore; Medtronic), Franseen-type needle (Acquire; Boston 
Table 3 Fine needle biopsy (FNB) needles.

\begin{tabular}{|l|l|}
\hline $\begin{array}{l}\text { Needle type (available gauge sizes), } \\
\text { manufacturer }\end{array}$ & Key features \\
\hline $\begin{array}{l}\text { Echotip ProCore (19G, 22G, 25G), } \\
\text { Cook Medical }\end{array}$ & $\begin{array}{l}\text { Reverse bevel: modified Menghini-type needle with a beveled side-slot near the needle tip. } \\
\text { Slot cutting edge directed backward to collect tissue during retrograde movement of the needle. }\end{array}$ \\
\hline $\begin{array}{l}\text { Echotip ProCore (20G), } \\
\text { Cook Medical }\end{array}$ & $\begin{array}{l}\text { Antegrade core trap: modified Menghini-type needle with a beveled side-slot near the needle tip. } \\
\text { Slot cutting edge directed forward to cut tissue during antegrade movement of the needle. }\end{array}$ \\
\hline $\begin{array}{l}\text { SharkCore (19G, 22G, 25G), } \\
\text { Medtronic }\end{array}$ & $\begin{array}{l}\text { Fork-shaped tip: end-cutting needle with a fork-shaped distal tip including six cutting edges and } \\
\text { an opposing bevel. No side-slot. }\end{array}$ \\
\hline $\begin{array}{l}\text { Acquire (22G, 25G), } \\
\text { Boston Scientific }\end{array}$ & $\begin{array}{l}\text { Franseen tip geometry: end-cutting needle with a crown-shaped distal tip including three symmetrical } \\
\text { beveled cutting edges. No side-slot. }\end{array}$ \\
\hline
\end{tabular}

Scientific), or 20G FNB needle with antegrade core trap (ProCore 20G; Cook Medical) is limited [63-71]. The chronologically first FNB needle, the trucut biopsy needle (QuickCore; Cook Medical) is not manufactured anymore and will not be discussed here.

FNA vs. reverse bevel needles

A total of 13 RCTs [9-21] compared FNA and reverse bevel needles in patients with various solid masses or LNs $[9,10,12,13$, $16,17,20]$, solid pancreatic masses $[14,15,18,21]$, or subepithelial lesions [11,19] (Table S1, online-only Supplementary material). These studies evaluated almost exclusively $22 \mathrm{G}$ and $25 \mathrm{G}$ needles, and sampling technique in most cases involved the use of stylet and suction. Rapid on-site cytologic evaluation (ROSE) was available in selected studies. One study compared FNA and reverse bevel needles of different diameter (22G FNA vs. $25 \mathrm{G}$ reverse-bevel) [16].

Diagnostic accuracy was evaluated in eight of these RCTs; none of them found a significant difference between the needles in the main analysis $[10,12,14-18,20]$. However, a subgroup analysis in one study suggested that reverse bevel needles, compared with FNA needles of the same diameter, offered a higher accuracy for malignancy in patients with pancreatic masses and a lower accuracy for malignancy in patients with LNs [20]. Another RCT found a higher accuracy of on-site diagnosis on samples obtained with reverse bevel needles, with no difference in the accuracy of final diagnosis [18]. Two metaanalyses did not show significant differences in diagnostic accuracy between FNA and reverse bevel needles, both overall (in patients with various solid masses or LNs) and specifically in patients with solid pancreatic masses (Table S2, online-only Supplementary material) [50,51].

Conclusions about the impact of needle type on sample adequacy and quality are hampered by inconsistent definitions of these outcomes across studies; however, there is some evidence to suggest that samples obtained with reverse bevel needles are more often adequate for histologic diagnosis and of higher histologic quality than those obtained with FNA needles of the same gauge (Table S1, online-only Supplementary material). Six RCTs showed that when compared with FNA needles, reverse bevel needles required fewer passes to obtain tissue adequate for histologic diagnosis [15, 20], core tissue speci- mens $[10,19]$, or samples adequate for diagnosis based on a combination of cytologic and histologic examination $[11,18]$. Also the rates of diagnostic samples [13], samples adequate for histologic diagnosis $[14,19]$, samples adequate for on-site cytologic evaluation [13], and sample histologic quality [14, 15] were higher for reverse bevel than for FNA needles. One RCT showed that samples obtained with reverse bevel needles were of lower histologic quality than samples obtained with FNA needles; however, this study compared a single pass with the reverse bevel needle with two passes with a FNA needle [17]. Seven RCTs found samples obtained with FNA and reverse bevel needles of comparable quality and/or adequacy [9-12, 16, 20, 21].

Two meta-analyses did not find significant differences between FNA and reverse bevel FNB needles in the rate of samples adequate for pathologic examination and in the rate of histologic core tissue procurement, both overall (various solid masses and LNs) and in patients with pancreatic masses; however, the number of needle passes to obtain a diagnostic sample was significantly lower for reverse bevel needles than for FNA needles (Table S2, online-only Supplementary material) [50, 51]. There were no significant differences in overall complications and technical failure [51].

A cost analysis in a decision tree model found that reverse bevel needles are cost-saving compared to FNA needles over a wide range of cost and outcome probabilities; however, this study used cost variables from the US that might not apply to other countries [13].

\section{Other types of FNB needles}

An RCT that compared the $19 \mathrm{G}$ reverse bevel needle with the 19G trucut needle in patients with various solid masses and parenchymal liver disease showed advantages of the former in terms of higher diagnostic accuracy for malignancy, higher rate of samples adequate for histologic diagnosis, higher technical success rate of the first pass, and lower rate of crossover to the other needle (Table S3, online-only Supplementary material) [22].

RCTs evaluating other FNB needles, such as the fork-tip needle [63-65,67-70], Franseen-type needle [66], or throughthe-needle biopsy forceps [72], are lacking. Studies in patients with pancreatic masses $[63,67]$, various pancreatic and 
nonpancreatic masses [64, 68, 70], or subepithelial masses [69] suggest that the fork-tip needle may confer advantages over FNA needles in terms of diagnostic accuracy [67] and/or sample adequacy and quality [63,64,67-69]; however, these studies are limited by retrospective design [64,67-70] or small number of evaluated patients [63]. A study in nondiseased cadaveric liver tissue showed that $19 \mathrm{G}$ and $22 \mathrm{G}$ fork-tip needles provide superior histologic yield, as measured by the number of portal tracts and tissue fragmentation, when compared with 19G FNA or 19G reverse bevel needles [71]. The Franseen-type needle was evaluated in only a single noncomparative study [66]. Studies evaluating the 20G FNB needle with antegrade core trap are not yet available.

FNA needles with side port

An RCT in patients with pancreatic masses that compared 22G FNA needles with and without a side port did not demonstrate significant differences in diagnostic accuracy for malignancy, or in sample adequacy or quality (Table S4, online-only Supplementary material) [23].

\section{Needle gauge}

25G FNA vs. 22G FNA

Eight RCTs compared EUS-FNA with 22G and 25G needles in patients with various solid masses and LNs $[24,25,27,28]$ or with solid pancreatic masses [26,29-31] (TableS5, online-only Supplementary material). The technique involved the use of stylet and suction.

Only one RCT demonstrated a significantly higher accuracy for the 25G needle [24]; the differences in accuracy observed in the remaining seven studies were nonsignificant [25-31]. No significant differences were found between the needles in terms of sample adequacy and quality. One study found that the $25 \mathrm{G}$ needle is easier to manipulate [26]; another one found that the $22 \mathrm{G}$ needle is superior in terms of needle visibility and technical performance [27]. In one study the adverse event rate was lower with the $25 \mathrm{G}$ needle [26]; no adverse events were reported in the remaining seven studies [24, 25, 27-31].

Studies comparing FNA with $25 \mathrm{G}$ and $22 \mathrm{G}$ needles were subject to four meta-analyses [52-55] that provided conflicting results (Table S6 online-only Supplementary material). The recent meta-analysis by Facciorusso et al. restricted to RCTs (7 studies published in 2009-2016) did not demonstrate significant differences between the needles in terms of sensitivity or specificity for malignancy in patients with solid pancreatic masses [52]. In contrast to this study, Xu et al., who analyzed studies from the same period ( 7 RCTs and 4 prospective nonrandomized studies), found higher sensitivity for pancreatic malignancy for the $25 \mathrm{G}$ needle with no significant difference in specificity [53]. The remaining two meta-analyses were published in 2013 , did not analyze recent data, and are limited by significant heterogeneity and inclusion of retrospective studies. The meta-analysis by Madhoun et al. (4 RCTs, 1 prospective and 3 retrospective studies published in 2009-2011) showed that the $25 \mathrm{G}$ needle was associated with higher sensitivity but similar specificity compared with the $22 \mathrm{G}$ needle [54]. However, when the retrospective study by Yusuf et al. [73], including
842 patients and markedly larger than the remaining evaluated studies, was removed from the analysis, the difference in sensitivity missed statistical significance. It was also nonsignificant when only prospective studies were analyzed. The meta-analysis by Affolter et al. (4 RCTs and 3 retrospective studies published in $2005-2011$, including two studies in patients with pancreatic and nonpancreatic masses) did not find significant difference in accuracy between the needles [55].

Conclusions from the discussed meta-analyses on outcomes other than diagnostic accuracy are limited. Low numbers of adverse events precluded safety analysis. Madhoun et al. did not find significant differences in needle malfunction rates [54]. A trend toward higher sample adequacy for the $25 \mathrm{G}$ needle shown by Affolter et al. [55] was not confirmed by Facciorusso et al. [52]. In addition, the sample adequacy analysis in the former study was based on heterogeneous data on various outcomes such as diagnostic yield, adequacy, or technical success rates that were inconsistently defined in the source studies.

\section{$25 G$ vs. $22 G$ reverse bevel needles}

An RCT in patients with solid pancreatic masses did not find significant differences between 25G and 22G reverse bevel needles in terms of accuracy for malignancy and in sample adequacy and quality (TableS7, online-only Supplementary material) [32].

\section{$19 G$ vs. thinner needles}

19G needles are used primarily to obtain samples with preserved tissue architecture adequate for histologic evaluation. These needles, as shown both in benchtop and clinical studies, are stiffer and more difficult to operate as compared to thinner needles, especially when sampling is performed with the scope in an angulated position, for example from the duodenum [33, $74,75]$. A 19G FNA needle made out of nitinol was shown to offer mechanical performance advantages in benchtop testing [75], but clinical evidence is limited and no comparative data are available [76].

Studies comparing $19 \mathrm{G}$ needles and thinner needles are scarce [33]. An RCT that compared EUS-FNA with 19G and 22G needles in patients with solid pancreatic masses did not demonstrate a significant difference in accuracy; however, a secondary analysis limited to technically successful cases found significantly higher accuracy for the 19G needle. This advantage, however, was offset by a higher technical failure rate of the $19 \mathrm{G}$ needle in pancreatic head masses. No clinically significant adverse events were reported (Table S8, online-only Supplementary material). A nonrandomized, prospective comparison of $19 \mathrm{G}$ and $22 \mathrm{G}$ needles in patients with mediastinal masses and lymph nodes did not show significant differences between the needles in the rate of diagnostic samples and in diagnostic accuracy [77]. The only RCT that compared the nitinol 19G and 25G FNA needles in patients with solid pancreatic masses was retracted from publication $[78,79]$.

Both 19G FNA and 19G reverse bevel needles have been evaluated in a number of noncomparative studies in patients with various solid masses [76,80-83], LNs [84], or subepithelial masses [85]. Sampling was technically feasible in $98 \%-100 \%$ 
of cases; however, patients were highly selected and sampling was performed transduodenally only in a small percentage of cases $(5 \%-32 \%)$. Core tissue samples adequate for histologic evaluation, including immunostaining when indicated, were obtained at a rate of $89 \%-100 \%$ when calculated per procedure $[80,81,84,85]$ or $79 \%-94 \%$ per single needle pass $[81,82]$. With the use of the nitinol 19G FNA needle, core tissue samples adequate for histologic examination were obtained in $94 \%$ of patients despite the fact that most lesions ( $89 \%$ ) were sampled transduodenally [76]. These data suggest that when sampling with the 19G needle is technically feasible, specimens adequate for histologic evaluation can be obtained in $>90 \%$ of cases. This figure is higher when indirectly compared to the rate at which histologic samples were obtained with the $22 \mathrm{G}$ reverse bevel needle $(69 \%-83 \%$ per procedure and $69-81 \%$ per single pass) $[12,15,19,20,32,86,87]$ or the $25 \mathrm{G}$ reverse bevel needle (32\%-88\% per procedure and $12 \%-69 \%$ per single pass) [ 14 , $32,88]$. In a series of patients with small $(<2 \mathrm{~cm})$ pancreatic lesions, core tissue specimens were obtained in $53 \%$ of cases using the $22 \mathrm{G}$ reverse bevel needle [89]. Good results - histologic samples obtained in $68 \%-98 \%$ of cases - have also been reported in several retrospective studies evaluating 22G FNA needles [90]; however, as discussed earlier, direct randomized comparisons suggest that $22 \mathrm{G}$ reverse bevel needles provide tissue of better histologic quality than FNA needles of the same gauge. It has to be emphasized that, in the studies under discussion, the definition of a "core tissue sample" or "sample adequate for histologic evaluation" has not been standardized.

\section{Rationale for recommendations}

There is high quality evidence from numerous RCTs and two meta-analyses that reverse bevel needles and FNA needles of the same gauge do not differ significantly in terms of diagnostic accuracy for malignancy. The discussed RCTs were not primarily designed to compare safety; however, adverse events occurred very rarely, with most studies reporting zero rates, and there is no evidence for differences in safety profiles of both types of needle. The panel recognized that selected studies have shown some advantages of reverse bevel needles over FNA needles, including higher quality of histologic specimens procured with the former and a lower number of needle passes required to obtain a diagnostic sample; however, the clinical significance of these advantages for the patient remain uncertain. It is also uncertain whether these advantages offset the higher cost of the reverse bevel needle. Therefore, the panel decided not to recommend the reverse bevel needles over FNA needles. No specific recommendations can yet be given about other types of FNB needles because of insufficient evidence.

All but one of the eight available RCTs failed to demonstrate significant differences between 25G and 22G FNA needles in diagnostic accuracy for malignancy; the results of four metaanalyses available on this topic are conflicting. There is consistent evidence that the cytologic quality of samples obtained with 25G FNA and 22G FNA needles is similar. No convincing advantages of $25 \mathrm{G}$ vs. $22 \mathrm{G}$ needle or vice versa in terms of their technical performance, ease of use, or safety profile have been demonstrated. All this probably holds true for the comparison of $25 \mathrm{G}$ vs. $22 \mathrm{G}$ reverse bevel needles, although evidence here is limited. In light of these data the panel decided to equally recommend the $25 \mathrm{G}$ and $22 \mathrm{G}$ needles for use in routine sampling of pancreatic masses, other solid masses, and LNs.

There is a growing interest in obtaining histologic rather than cytologic samples from pancreatic masses, subepithelial tumors, and other target lesions [2]. Although larger-caliber needles may provide better specimens for this purpose when compared to thinner needles, the use of the former is limited by their stiffness, especially when sampling is performed from the duodenum. To overcome this problem, flexible nitinol 19G needles have been designed. Another option is to use thinner, $22 \mathrm{G}$ (or 25G) needles of special design to procure histologic specimens (FNB needles). Studies comparing these approaches are lacking, and there is only low quality, indirect evidence to suggest that when the priority is to obtain a core tissue sample, and sampling with a $19 \mathrm{G}$ needle is feasible, these needles should be preferred over thinner needles. Because various types of $19 \mathrm{G}$ needles (standard FNA, nitinol FNA, and FNB) have not been directly compared, there is not enough evidence to recommend one type over another. When sampling with a 19G needle is not technically feasible, there is low quality evidence to suggest that a $22 \mathrm{G}$ reverse bevel needle should be used rather than a $22 \mathrm{G}$ FNA needle or a $25 \mathrm{G}$ needle. Because of the lack of evidence no recommendation can be given at present on FNB needles other than the reverse bevel needle.

\section{The use of suction}

\section{RECOMMENDATION}

ESGE recommends using 10-mL syringe suction for EUSguided sampling of solid masses and LNs with $25 \mathrm{G}$ or 22G FNA needles (high quality evidence, strong recommendation) and other types of needles (low quality evidence, weak recommendation).

\section{RECOMMENDATION}

ESGE suggests neutralizing residual negative pressure in the needle before withdrawing the needle from the target lesion (moderate quality evidence, weak recommendation).

\section{Summary of evidence}

\section{Standard suction}

The impact of negative pressure, applied with a 10 - or $20-\mathrm{mL}$ suction syringe connected to the needle, on the results of EUSguided sampling was evaluated in four RCTs (Table S9, onlineonly Supplementary material) [34-37]. These studies predominantly used 22G FNA needles. Three RCTs (two in patients with pancreatic masses [34,35] and one in patients with various mediastinal and abdominal lesions [36]) showed that $10-\mathrm{mL}$ suction improves sensitivity [34-36] and accuracy [34, 
35] for malignancy compared to no suction. One of these studies also showed that $20-\mathrm{mL}$ suction is superior to $10-\mathrm{mL}$ suction [34]. In contrast, in an RCT in patients with mediastinal or abdominal lymphadenopathy using suction did not influence the probability of obtaining a correct diagnosis [37]. Suction increases the rate of procuring diagnostic samples and the sample cellularity. It may also increase sample bloodiness; however, this fact does not appear to affect the diagnostic performance [34-37].

\section{High negative pressure}

Using high negative pressure (50-mL vacuum syringe) rather than standard suction $(10-\mathrm{mL})$ during EUS-FNA of pancreatic masses did not improve accuracy for malignancy in an RCT that evaluated $25 \mathrm{G}$ needles. Samples obtained with high negative pressure were more likely to be adequate for histologic diagnosis and contained more blood. There was no difference in sample contamination by gastrointestinal tract cells (Table S9, online-only Supplementary material) [38].

\section{"Wet suction"}

The "wet suction" technique was developed to enhance tissue acquisition by applying principles of fluid dynamics to aspiration technique [91]. The wet technique involves pre-flushing the needle with saline to replace the column of air with liquid which is less compressible than gas and better transmits to the needle tip the negative pressure applied to the proximal port of the needle $[39,91]$. In an RCT that compared the wet technique vs. standard suction FNA in patients with various solid masses and LNs, the wet suction technique improved sample adequacy and quality. The impact on diagnostic accuracy was not evaluated (Table S9, online-only Supplementary material) [39].

\section{"Stylet slow-pull”}

It has been suggested that slow removal of the stylet during sampling creates minimal negative pressure within the needle that enhances sampling. This technique, referred to as "stylet slow-pull" has not been standardized as to the speed of stylet removal, and the suction force it generates is estimated at only $5 \%$ of the force generated with the standard suction method [92]. Retrospective studies suggested advantages over standard suction $[93,94]$; however, a nonrandomized prospective study [95] and an RCT (available only in abstract form) [96] did not show significant differences between standard suction and stylet slow-pull techniques in terms of diagnostic accuracy.

\section{Eliminating the residual negative pressure}

A benchtop study showed that despite closing of the stopcock of the suction syringe, negative pressure persists in the needle. This residual pressure can be neutralized by disconnecting the syringe stopcock from the needle port before withdrawing the needle from the target lesion [40]. In an RCT in patients with pancreatic masses, this method was shown to decrease sample contamination with gastrointestinal tract cells and to increase sensitivity for malignancy (Table S9, online-only Supplementary material) [40].

\section{Impact of suction on FNB results}

The impact of suction on FNB results has not been evaluated in RCTs and it remains uncertain whether the results from studies using FNA needles discussed above can be extrapolated to sampling with FNB needles. Most studies that evaluated the reverse bevel needle used $10-\mathrm{mL}$ suction $[12,15,17,18,20-22,32,81$, $83,86]$ or the stylet slow-pull technique $[14,16,19,88]$. In a benchtop study using chicken tenderloin and liver, the amount of tissue obtained with the $22 \mathrm{G}$ reverse bevel needle depended on the suction applied to the needle. Sampling using suction (10-mL) procured significantly more tissue than sampling using the stylet slow-pull method and sampling without suction; stylet slow-pull was more effective than no suction [97]. In contrast, in a retrospective study that used the $22 \mathrm{G}$ reverse bevel needle in patients with solid pancreatic masses, the stylet slow-pull technique provided samples of superior cellularity (higher proportion of tumor cells and more tissue microfragments) than the standard suction technique. Better sample quality, however, did not translate into a higher rate of diagnostic samples [98]. The effect of suction on results of sampling with fork-tip or Franseen-type needles has not been evaluated. Studies that assessed these needles used various approaches, including no suction $[65,66]$, stylet slow-pull technique [65, $67,69]$, or syringe suction $[67,70]$.

\section{Rationale for recommendations}

Results of three RCTs indicate that using $10 \mathrm{~mL}$ of suction during sampling with 22G or 25G FNA needles improves accuracy and/or sensitivity for malignancy when compared to the nosuction technique. The evidence in favor of suction is strongest for 22G FNA needles in the setting of pancreatic masses and it is less clear for other target lesions, especially LNs, and for sampling with 25G FNA needles. Comparative studies to specifically evaluate the effect of suction on sampling with 19G FNA needles are lacking; however, suction was used in most studies that evaluated these needles. The same holds true for the reverse bevel needles. Although the evidence on the effect of using suction is limited in some areas, there are also no perceivable risks or disadvantages of this technique. Increased sample bloodiness shown in some studies does not appear to affect diagnostic performance and as a result does not constitute a significant problem. Therefore, the panel decided to recommend using suction for all indications and all needle gauges and types.

Neutralizing residual negative pressure in the needle before withdrawing the needle from the target lesion was shown to improve sensitivity for malignancy. Although the mechanism behind this effect remains uncertain and the evidence is limited to a single RCT, the panel decided to recommend this simple maneuver, because it is not associated with any inconvenience or burden.

There is limited evidence that suction applied with a $20-\mathrm{mL}$ or 50 -mL syringe or using the wet suction technique may confer some advantages over standard suction with a $10-\mathrm{mL}$ syringe. These techniques can be considered, especially if the standard suction technique fails to obtain an adequate sample, but confirmatory data from other studies are needed before they can 
be recommended for routine use. There is not enough evidence to recommend for or against using the stylet slow-pull technique.

\section{Needle stylet}

\section{RECOMMENDATION}

ESGE does not recommend for or against using the needle stylet for EUS-guided sampling of solid masses and LNs with FNA needles (high quality evidence, strong recommendation) and suggests using the needle stylet for EUS-guided sampling with FNB needles (low quality evidence, weak recommendation).

\section{Summary of evidence}

The effect of using a needle stylet during EUS-FNA was evaluated in four RCTs [41-44] (Table S10, online-only Supplementary material), one prospective nonrandomized crossover study [99], and two retrospective studies $[100,101]$. These studies included patients with solid lesions (predominantly pancreatic masses) and LNs, and evaluated outcomes related to specimen quality such as sample adequacy, cellularity, gastrointestinal cell contamination, and bloodiness. With minor and insignificant exceptions sampling technique involved using 22G needles, suction, and ROSE; 25G needles were used in only 23 patients in one study [43].

None of the individual studies or their meta-analysis [56] showed any advantages of using the stylet. On the contrary, differences in secondary outcome measures favoring not using the stylet were shown in one study, including a higher rate of sample adequacy and lower rate of bloody samples [99]. The significance of these findings is uncertain because the remaining studies [41, 43, 44, 100,101] and the meta-analysis [56] did not show advantages of stylet-free technique. The stylet is also used to express the aspirate from the needle; however, this method offered no advantage in terms of specimen quality when compared to flushing the needle with air in a slow controlled manner. In fact, sample bloodiness was higher when samples were expressed by reinserting the stylet [35] (Table S10, online-only Supplementary material).

The impact of the needle stylet on FNB results has not been evaluated in RCTs and it remains uncertain whether the results from studies using FNA needles discussed above can be extrapolated to sampling with FNB needles. Most studies that evaluated the reverse bevel needle used the stylet [12,14-20,22, $81,83,86]$. Data on stylet-free sampling with this needle are very limited and do not allow for any comparison [21,83]. Studies evaluating the fork-tip needle used the stylet $[63,65,69]$ or failed to mention whether or not it was used $[64,67,68,70]$. In the only study evaluating the Franseen-type needle, the stylet was used only during the first needle pass [66].

\section{Rationale for recommendations}

Potential advantages of using the stylet, such as preventing clogging of the needle and contamination of the sample with gastrointestinal cells, or easier and controlled expressing of the sample from the needle, have not been proven and there is high quality evidence that sampling using 22G FNA needles with or without the stylet provides samples of similar quality and adequacy. On the other hand, potential disadvantages, such as the risk of needlestick injury during stylet manipulation, increased procedure time, and decreased needle flexibility have not been evaluated and their significance remains uncertain. In this situation, the panel decided not to recommend for or against using the stylet for sampling with FNA needles, leaving this to the discretion of the endosonographer. Despite lack of comparative evidence the panel suggested using the stylet for sampling with FNB needles because only limited data exist on stylet-free technique in this setting.

\section{Targeting specific parts of the lesion}

\section{RECOMMENDATION}

ESGE suggests fanning the needle throughout the lesion when sampling solid masses and LNs (moderate quality evidence, weak recommendation).

\section{Summary of evidence}

\section{Sampling from the periphery vs. central part of the lesion}

In an RCT in patients with suspected malignant LNs, aspiration from the edge of the LN, compared with the center, did not increase the likelihood of a correct diagnosis (Table S11, onlineonly Supplementary material) [37].

\section{Fanning vs. standard targeting technique}

In an RCT in patients with pancreatic masses, use of a fanning technique, compared to the standard targeting technique, decreased the number of needle passes required to establish the diagnosis and increased the proportion of patients in whom an on-site diagnosis was achieved on the first pass. The difference in accuracy for malignancy in favor of the fanning technique only narrowly missed statistical significance (TableS11, online-only Supplementary material) [46]. In this RCT the fanning technique involved positioning the needle at four different areas within the mass and performing four back-and-forth movements in each of them to procure tissue $(4 \times 4)$. The standard targeting technique involved positioning the needle at one location within the mass and performing 16 back-and-forth movements to procure tissue $(1 \times 16)$ [46].

\section{Contrast harmonic EUS-guided sampling}

Contrast harmonic EUS can be used to guide sampling by distinguishing viable, enhancing tumor tissue from nonenhancing necrotic areas; however, in a small RCT in patients with pancreatic masses this technique did not improve sample adequacy, sensitivity, and accuracy for malignancy when compared to 
sampling under conventional EUS guidance. (Table S11, onlineonly Supplementary material) [45]. A prospective, nonrandomized study [102] and a retrospective study [103] in patients with a pancreatic mass also failed to show significant advantages of using contrast harmonic EUS guidance.

\section{Rationale for recommendations}

Fanning the needle allows for targeting multiple areas within the mass during each needle pass and hence reduces the chance of sampling error. The technique is not associated with an additional risk or cost. Therefore the panel recommended its use, although the evidence is limited to one RCT in patients with pancreatic masses that showed advantages of fanning in terms of sample adequacy but failed to show a significant impact on diagnostic accuracy. Because of insufficient evidence, the panel did not give a recommendation on contrast harmonic EUS-guided sampling.

\section{On-site cytologic evaluation}

\section{RECOMMENDATION}

ESGE equally recommends EUS-guided sampling with or without on-site cytologic evaluation (moderate quality evidence, strong recommendation).

\section{Summary of evidence}

The effects of ROSE on FNA results were evaluated in two RCTs in patients with solid pancreatic masses (Table S12, online-only Supplementary material) $[47,48]$. In both studies a fixed number of seven needle passes was performed in patients randomized to FNA without ROSE and this number was significantly higher compared to the number of passes directed by the onsite cytopathologist. Other outcome measures, including diagnostic accuracy $[47,48]$ and sample adequacy and quality [47] did not differ between these two approaches. The lower number of needle passes in the on-site directed approach did not translate into lower number of adverse events or shorter procedural time [47]. A post hoc analysis of one of these RCTs did not find significant differences in cumulative sensitivity for malignancy after each subsequent needle pass between groups with and without ROSE [104]. On-site evaluation did not reduce the cost of EUS-guided sampling and in fact may increase it [47, 48]. The results of four meta-analyses of mostly observational studies in patients with pancreatic masses are conflicting. Two of them found improvement in EUS-FNA adequacy rates [58] and diagnostic accuracy [57] associated with the use of ROSE. The remaining two failed to confirm these advantages $[59,60]$.

According to a recent survey on practice patterns in EUSguided sampling, ROSE was available to $48 \%$ of responders from Europe, $55 \%$ of responders from Asia and almost all responders (98\%) from the US [105]. The barriers to implementing this service include limited pathology staffing, costs, additional procedure time, and non-belief in its additional value [105].

\section{Rationale for recommendations}

ROSE is unavailable in about half of the EUS centers in Europe. The Guideline panel recognized that selected observational studies have shown advantages of ROSE, including increased diagnostic yield and decreased need for repeat sampling; however, evidence from two recent RCTs indicate that ROSE does not improve results of EUS-guided sampling, and the results of four meta-analyses on this topic are conflicting. Therefore, the panel did not find sufficient reasons to recommend that centers not using ROSE should change their practice.

\section{Number of needle passes in the absence of on-site evaluation}

\section{RECOMMENDATION}

When on-site cytologic evaluation is unavailable, ESGE suggests performance of three to four needle passes with an FNA needle or two to three passes with an FNB needle (low quality evidence, weak recommendation).

\section{Summary of evidence}

Per-pass analyses of data from recent prospective studies in patients with pancreatic masses showed that three to four passes with an FNA needle or two to three passes with the reverse bevel needle are sufficient to achieve high rates of diagnostic samples and high sensitivity for malignancy, both exceeding $90 \%$ (Table S13, online-only Supplementary material) $[15,18,21$, $46,88,104]$. A lower number of passes was associated with suboptimal performance. On the other hand, increasing the number of passes beyond four (FNA) or three (reverse bevel needle) did not improve or only marginally improved the results [18, $88,104]$. For tumors $\leq 2 \mathrm{~cm}$ in size, the cumulative sensitivity after four FNA passes was significantly lower than for tumors $>2 \mathrm{~cm}$; however, also in the setting of smaller tumors, increasing the number of passes beyond four only marginally improved the sensitivity (Table S13, online-only Supplementary material) [104]. Per-pass analysis in patients with lymphadenopathy found that sensitivity for malignancy reaches $100 \%$ after three passes with an FNA needle [37]. Per-pass analyses for target lesions other than pancreatic masses or lymph nodes are missing.

Methods of gross visual (macroscopic) inspection of the specimen obtained during EUS-guided sampling, to determine its adequacy for cytologic or histologic evaluation, have not been standardized and the evidence on their usefulness to guide the number of needle passes is limited and conflicting. A recent prospective study evaluating specimens obtained with a 19G FNA needle found that the presence of a macroscopically visible core of $\geq 4 \mathrm{~mm}$ in length accurately estimated the presence of a histologic core and was associated with significantly higher diagnostic performance in the histologic and cytologic evaluations [82]. Studies using $22 \mathrm{G}$ or $25 \mathrm{G}$ needles failed to show efficacy of macroscopic evaluation $[88,106]$. 


\section{Rationale for recommendations}

Previous ESGE guidelines recommended performing three needle passes for lymph nodes and liver lesions and at least five passes for solid pancreatic masses [1]. These recommendations were based on limited evidence from older studies. More robust evidence from recent studies indicates that two to three passes with the reverse bevel needle or three to four passes with the FNA needle are an adequate approach in patients with solid pancreatic masses. There is not sufficient evidence to recommend that these numbers should be different for other target lesions. Although selected studies, in which a single pass with the reverse bevel needle or two passes with the FNA needle were performed, reported good results [17, 25, 29], the Guideline panel found this evidence insufficient to recommend a number of passes lower than indicated above. Because of the lack of robust evidence on the efficacy of macroscopic visual inspection of the specimen to guide the number of needle passes, no recommendation is given on this topic.

\section{Sampling of pancreatic cystic lesions}

\section{RECOMMENDATION}

For diagnostic sampling of pancreatic cystic lesions without a solid component, ESGE suggests emptying the cyst with a single pass of a $22 \mathrm{G}$ or $19 \mathrm{G}$ needle (low quality evidence, weak recommendation).

\section{RECOMMENDATION}

For pancreatic cystic lesions with a solid component, ESGE suggests sampling of the solid component using the same technique as in the case of other solid lesions (low quality evidence, weak recommendation).

\section{Summary of evidence}

The role of EUS-guided sampling in pancreatic cystic lesions has been evaluated in numerous studies; however, most of them focused on various aspects of cyst fluid analysis rather than on the sampling technique itself [107-110]. In most centers the technique involves the use of $19 \mathrm{G}$ or 22G FNA needles and an attempt to empty the cyst as much as possible with a single needle pass, in order to maximize diagnostic yield and minimize the risk of infection [105]. This approach, based on expert opinion, has never been adequately evaluated, and its effectiveness remains unproven. The risk of adverse events in studies in which multiple needle passes were performed was similar to that in studies in which a single-pass technique was used $(2.17 \%[95 \% \mathrm{Cl} 1.21 \%-3.40 \%]$ and $3.45 \%$ [95\%Cl $1.41 \%-6.33 \%]$, respectively) [111]. Larger-caliber needles facilitate aspiration of thick or viscous fluid, but are more difficult to operate. Studies directly comparing needles of various gauge sizes are not available. A recent meta-analysis estimated that the risk of adverse events was similar with $19 \mathrm{G}$ and $22 \mathrm{G}$ needles $(5.84 \%$ [ $95 \% \mathrm{Cl} 0.88 \%-13.64 \%$ ] and $2.38 \%$
[95\% Cl $1.38 \%-3.63 \%$ ], respectively) [111]. Failure to aspirate the fluid with a $22 \mathrm{G}$ needle because of fluid viscosity has been reported in up to $20 \%$ of patients evaluated in consecutive case series [112, 113]. More than one needle pass into a cyst without a solid component did not result in a significantly higher rate of samples adequate for cytologic diagnosis when compared to a single pass (50\% vs. $29 \%$; $P=0.08$ ) [114].

Targeted cyst wall puncture after aspiration of cyst fluid was shown to provide a specimen adequate for cytologic or cytologic/histologic evaluation in $65 \%-81 \%$ of cases, and to offer an additional incremental diagnostic yield for mucinous cyst of $29 \%-37 \%$ over cyst fluid analysis/cytology alone [112,113, 115]. Non-severe adverse events were observed in 1.5\%-4.5\% of cases. These results were obtained with 22G FNA $[113,115]$ or 22G reverse bevel needles [112], and data for other needle gauges are lacking. The role of this technique for diagnosis of malignant cyst has not been established because of the low number of reported cases.

When a cystic lesion contains a solid component, samples from the solid part are more often adequate for diagnosis than fluid aspirates $[112,114]$. The rate of samples adequate for cytologic diagnosis increased significantly from $44 \%$ with one needle pass to $78 \%$ with more than one pass $(P=0.016)$ [114].

Experience with through-the-needle forceps biopsy of the cyst wall or mural nodules is limited to case reports and small pilot series and this technique remains investigational [72, $116,17]$.

\section{Rationale for recommendations}

There are no RCTs or nonrandomized comparative studies evaluating the technical aspects of sampling of pancreatic cystic lesions. Consequently, the evidence available on this topic is limited and of low quality. Despite these limitations, the Guideline panel decided to suggest using the sampling technique widely employed at many centers that involves emptying the cyst with a single pass of a $19 \mathrm{G}$ or $22 \mathrm{G}$ needle. $19 \mathrm{G}$ needles are preferred for large cysts and for cysts filled with presumably thick or viscous fluid, although no evidence-based criteria for cyst size and appearance can be given. Because of limited evidence on the efficacy and safety of targeted cyst wall puncture, the panel did not recommend routine implementation of this technique. Solid parts of the cystic lesions should be sampled using techniques recommended for solid pancreatic masses; however, it has to be noted that the term "solid component" is not well defined and may overlap in some studies with "mural nodule" or "thickened cyst wall." There is insufficient evidence to issue a recommendation on through-the-needle forceps biopsy of the cyst wall.

\section{Safety of EUS-guided sampling}

\section{Patients on antithrombotic therapy}

Issues related to the management of patients on antithrombotic therapy undergoing EUS-guided sampling are covered in the Guideline recently issued by ESGE and the British Society of Gastroenterology (BSG) [118]. Readers are referred to this document for detailed information. Briefly, the ESGE/BSG 
Guideline classifies EUS-guided sampling as a high risk procedure and recommends against sampling in patients on P2Y12 receptor antagonists or oral anticoagulants including vitamin $\mathrm{K}$ antagonists and direct oral anticoagulants. If sampling is indicated, these medications should be temporarily discontinued for an appropriate drug-specific interval. The need for bridge therapy with low molecular weight heparin or switching to acetylsalicylic acid should be determined on the basis of the underlying indication for antithrombotic therapy and the risk for thromboembolic events. EUS-guided sampling can be performed in patients on low dose acetylsalicylic acid therapy.

\section{Antibiotic prophylaxis}

\section{RECOMMENDATION}

ESGE does not recommend antibiotic prophylaxis for EUSguided sampling of solid masses or LNs (low quality evidence, strong recommendation).

\section{RECOMMENDATION}

ESGE suggests antibiotic prophylaxis with fluoroquinolones or beta-lactam antibiotics for EUS-guided sampling of cystic lesions (low quality evidence, weak recommendation).

\section{Summary of evidence}

Infectious adverse events related to EUS-guided sampling of solid lesions performed through the wall of the upper gastrointestinal tract are very rare $[1,119,120]$. No studies systematically evaluated antibiotic prophylaxis in this setting. The incidence of infectious adverse events following lower gastrointestinal tract EUS-FNA in a large prospective study was about $1 \%$ and did not differ between patients who had or had not received antibiotic prophylaxis administered at the discretion of the endoscopist [121].

Prophylaxis with fluoroquinolones or beta-lactam antibiotics was routinely used in the majority of studies on sampling of pancreatic cystic lesions; however, the effectiveness of this preventive measure has never been proven $[111,122]$. The optimal choice of drug and dosage regimen has not been adequately studied. Most studies used an initial intravenous dose followed by oral administration for 3-5 days; however, there is limited evidence from two noncomparative studies that a single intravenous dose may be sufficient $[123,124]$.

\section{Rationale for recommendations}

Antibiotic prophylaxis is commonly used for EUS-guided sampling of pancreatic cystic lesions (and cystic lesions in other locations); however, this approach is based on long-standing clinical practice and very limited evidence. On the other hand there is not sufficient evidence to recommend against prophylaxis and in this situation the Guideline panel conservatively decided to uphold its previous recommendation for prophylaxis. There is no evidence to recommend prophylaxis for sampling of solid masses or LNs.

\section{Specimen processing}

\section{RECOMMENDATION}

ESGE suggests that evaluation of tissue obtained by EUSguided sampling should include histologic preparations (e. g., cell blocks and/or formalin-fixed and paraffin-embedded tissue fragments) and not be limited to smear cytology (low quality evidence, weak recommendation).

\section{Methods of specimen processing}

Samples obtained by EUS-guided sampling may contain free cells, cell groups, and macroscopically visible tissue fragments, together with blood clots which themselves may contain all of the aforementioned. Samples may be processed for cytology or histology. In classical terms, cytology is the study and diagnosis of cells, received in liquid or on prepared slides. Larger tissue fragments including large groups of cells and stroma are not easily interpretable in a cytologic preparation because they are too thick and are usually ignored. Histology is the study and diagnosis of pieces of tissue, usually fixed in formalin and processed in a paraffin wax block. This is suitable for large fragments including stroma, but with routine processing, loose cells and small groups of cells are likely to be lost.

Once the sample is obtained it can be used to prepare direct smears and/or submitted to the laboratory in liquid. Direct smears are prepared in the endoscopy suite by extruding the needle content onto a glass slide and spreading the material in an evenly thin way. Smears may be allowed to dry or be fixed immediately by spray fixation or immersion into $95 \%$ alcohol. Unfixed smears are a potential biohazard and should be handled accordingly. For the preparation of a liquid sample the material is expressed into a liquid that could be saline, cell culture medium, or a fixative. If a fixative is not used, the sample should be rapidly transported to the laboratory and prepared. Although keeping the sample cool in a fridge will delay cellular degeneration, for optimal results delays should be minimized. Popular fixatives include alcohol and proprietary alcohol-based fixatives. These fixatives ensure good preservation and allow for more time to reach the laboratory. It also means that the material is available for further studies. Formalin may also be used but is not considered optimal for cytological purposes. However, it has the advantage of being the usual fixative for histologic samples and the fixative for which further immunohistochemistry is optimized. Liquid samples may be used for direct smear preparations or spun down to concentrate the material. This may be done either by a cytospin technique, or by using a proprietary liquid-based cytology machine (thin-layer liquidbased cytology). Liquid samples also allow for the making of a cell block. This is constructed by taking all or part of the spun down deposit from the liquid sample, forming a hardened structure by one of several different methods and putting it 
into a paraffin wax block. The material is then processed as a normal histologic specimen, cut and stained. The material is also then available for further ancillary tests if required, and also preserved for future studies.

Methods for collecting tissue fragments for histologic examination include expelling the specimen directly into a fixative, or onto a glass slide or into saline and picking up tissue fragments to immerse them into a fixative. Tumor tissue is usually whitish; however, red coagula may also contain tumor tissue. Collecting tissue fragments for histology does not seem to interfere with further cytologic evaluation of the remaining specimen. A liquid sample may also contain clearly visible tissue fragments or clots that may be removed in the laboratory from the liquid and processed separately in a conventional paraffin block.

\section{Summary of evidence}

Handling and processing of the specimens obtained by EUSguided sampling have not been standardized and vary considerably between centers [105]. They may also vary depending on the target lesions being sampled and whether or not ROSE is used. According to a recent international survey, $65 \%$ of the responding endosonographers prepare direct cytology smears. Proprietary fixatives, alcohol or saline are used for liquid-based cytology. Formalin is mostly used to preserve FNB or histologic tissue specimens. In order to increase diagnostic yield, most respondents (>70\%) also prepare and analyze tissue cores after FNA or cytologic material after FNB [105].

Methods used for specimen processing were compared in several, mostly observational studies in patients with pancreatic masses $[49,125-134]$, subepithelial masses [133], or LNs $[37,128,133,135]$ (TableS14, online-only Supplementary material). These studies predominantly used 22G FNA needles. Comparison was made by: (i) splitting the sample and processing separately by different methods; (ii) using different samples collected from the same lesion and processed differently; or (iii) by indirectly comparing results obtained with different methods in different patients and time periods. All these methods have inherent limitations.

Cell block preparation was shown to be superior to direct smear cytology $[125,129,135]$ or liquid-based cytology [125] in terms of sensitivity $[125,129,135]$, accuracy $[125,129$, $135]$, and negative predictive value $[125,129]$ for malignancy. Combination of direct smears and cell block preparation was shown to be superior to smears alone $[131,132]$. Two studies did not find significant differences between the cell block preparation and the direct smear methods $[37,127]$. The technical details of cell block preparation substantially varied between the studies.

Direct comparisons of direct smear cytology and thin-layer liquid-based cytology, including one crossover RCT [49], showed the former technique to be more sensitive $[49,125$, $130]$, more accurate $[49,125,128]$, and to have a higher negative predictive value $[49,125]$ for malignancy in patients with pancreatic masses or suspected LNs. The combination of liquid-based and direct smear cytology was not superior to direct smear cytology alone [49].
Combined cytologic and histologic evaluation was shown to have higher sensitivity [134] or accuracy [133] when compared to either cytologic or histologic evaluation alone.

\section{Rationale for recommendations}

Evidence from nonrandomized studies indicates that acquisition of tissue for cell blocks increases the diagnostic accuracy of EUS-guided sampling. Preparation and evaluation of cell blocks is a routine approach in many EUS centers. Core tissue specimens and tissue fragments isolated from the samples are increasingly often processed as formalin-fixed and paraffinembedded histologic specimens. The driver behind this is not only to improve the diagnostic accuracy for malignancy, but the increasing requirement to have material available for ancillary studies, especially immunohistochemistry. Although immunohistochemical examination may be done on smears or liquid material, in most laboratories the methods are primarily set up and antibodies validated for use in paraffin-embedded material. Further, in some areas there is also a growing requirement for molecular testing, and having paraffin-embedded cell block or core tissue specimens ensures that material is preserved for this purpose as well. The evidence in this field is limited; however, the panel felt that there is a potentially big advantage to getting histologic material, through preparing cell blocks and/or extracting visible tissue fragments, and recommended this approach for routine use. Because the methods of specimen handling and processing have not been standardized and vary across centers, close cooperation between the endosonographer, the pathologist, and the pathology laboratory is essential to ensure that all diagnostic material is salvaged and processed in the most efficient way, both for diagnosis and other requirements.

\section{Disclaimer}

ESGE guidelines represent a consensus of best practice based on the available evidence at the time of preparation. They may not apply in all situations and should be interpreted in the light of specific clinical situations and resource availability. Further controlled clinical studies may be needed to clarify aspects of the statements, and revision may be necessary as new data appear. Clinical consideration may justify a course of action at variance to these recommendations. ESGE guidelines are intended to be an educational device to provide information that may assist endoscopists in providing care to patients. They are not rules and should not be construed as establishing a legal standard of care or as encouraging, advocating, requiring, or discouraging any particular treatment. 


\section{Competing interests}

M. Barthet has provided consultancy and research support to Boston Scientific (from September 2015). S. Carrara has provided a paid lecture/course for Boston Scientific and for Olympus (2016). P. Deprez is providing paid consultancy to Boston Scientific and to Cook (January 2016 to December 2017, for both); his department is receiving sponsorship from Boston Scientific, Olympus, and Cook (January 2016 to December 2017, for all). J. Iglesias-Garcia has been a speaker and provided teaching activities for Boston Scientific (from 2016). B. Napoleon has received fees from Boston Scientific for educational workshops (2014 to present), and fees from Olympus for organisation of EUS 2016; his department has received support from Olympus for the organization of a meeting on contrast EUS (2015). J.E. van Hooft's department is currently receiving research grants from Cook Medical, Boston Scientific, and Olympus; since 2015 she has been a member of EUS platform, a national network of professionals. G.P. Aithal, P.G. Arcidiacono, P. Bastos, J.-M. Dumonceau, P. Eisendrath, G. FernándezEsparrach, A. Fornelli, A. Gines, C. Hassan, C. Jenssen, P. Kaye, A. Larghi, M. Polkowski, and A. Seicean have no competing interests.

\section{References}

[1] Polkowski M, Larghi A, Weynand B et al. Learning, techniques, and complications of endoscopic ultrasound (EUS)-guided sampling in gastroenterology: European Society of Gastrointestinal Endoscopy (ESGE) Technical Guideline. Endoscopy 2012; 44: 190 - 206

[2] Dumonceau JM, Deprez PH, Jenssen C et al. Indications, results, and clinical impact of endoscopic ultrasound (EUS)-guided sampling in gastroenterology: European Society of Gastrointestinal Endoscopy (ESGE) Clinical Guideline - Updated January 2017. Endoscopy 2017; 49: $695-714$

[3] Guyatt G, Oxman AD, AkI EA et al. GRADE guidelines: 1. Introduction - GRADE evidence profiles and summary of findings tables. J Clin Epidemiol 2011; 64: 383-394

[4] Balshem H, Helfand M, Schunemann HJ et al. GRADE guidelines: 3. Rating the quality of evidence. J Clin Epidemiol 2011; 64: 401 - 406

[5] Andrews ], Guyatt G, Oxman AD et al. GRADE guidelines: 14. Going from evidence to recommendations: the significance and presentation of recommendations. J Clin Epidemiol 2013; 66: 719-725

[6] Andrews JC, Schunemann HJ, Oxman AD et al. GRADE guidelines: 15 . Going from evidence to recommendation - determinants of a recommendation's direction and strength. J Clin Epidemiol 2013; 66: $726-735$

[7] Dumonceau JM, Hassan C, Riphaus A et al. European Society of Gastrointestinal Endoscopy (ESGE) Guideline Development Policy. Endoscopy 2012; 44: 626-629

[8] Vege SS, Ziring B, Jain R et al. American Gastroenterological Association Institute guideline on the diagnosis and management of asymptomatic neoplastic pancreatic cysts. Gastroenterology 2015; 148: $819-822$

[9] Othman MO, Abdelfatah MM, Padilla O et al. The cellularity yield of three different 22-gauge endoscopic ultrasound fine needle aspiration needles. Diagn Cytopathol 2017; 45: 426-432

[10] Lee BS, Cho CM, Jung MK et al. Comparison of histologic core portions acquired from a core biopsy needle and a conventional needle in solid mass lesions: a prospective randomized trial. Gut Liver 2017; 11: $559-566$

[11] Han JP, Lee TH, Hong SJ et al. EUS-guided FNA and FNB after on-site cytological evaluation in gastric subepithelial tumors. J Dig Dis 2016; 17: $582-587$
[12] Sterlacci W, Sioulas AD, Veits L et al. 22-gauge core vs 22-gauge aspiration needle for endoscopic ultrasound-guided sampling of abdominal masses. World J Gastroenterol 2016; 22: 8820 - 8830

[13] Aadam AA, Wani S, Amick A et al. A randomized controlled cross-over trial and cost analysis comparing endoscopic ultrasound fine needle aspiration and fine needle biopsy. Endosc Int Open 2016; 4: E497E505

[14] Kamata K, Kitano M, Yasukawa S et al. Histologic diagnosis of pancreatic masses using 25-gauge endoscopic ultrasound needles with and without a core trap: a multicenter randomized trial. Endoscopy 2016; 48: 632-638

[15] Alatawi A, Beuvon F, Grabar S et al. Comparison of 22G reversebeveled versus standard needle for endoscopic ultrasound-guided sampling of solid pancreatic lesions. United European Gastroenterol 2015; $3: 343-352$

[16] Mavrogenis G, Weynand B, Sibille A et al. 25-gauge histology needle versus 22 -gauge cytology needle in endoscopic ultrasonographyguided sampling of pancreatic lesions and lymphadenopathy. Endosc Int Open 2015; 3: E63 - E68

[17] Vanbiervliet G, Napoleon B, Saint Paul MC et al. Core needle versus standard needle for endoscopic ultrasound-guided biopsy of solid pancreatic masses: a randomized crossover study. Endoscopy 2014; 46: $1063-1070$

[18] Lee YN, Moon JH, Kim HK et al. Core biopsy needle versus standard aspiration needle for endoscopic ultrasound-guided sampling of solid pancreatic masses: a randomized parallel-group study. Endoscopy 2014; 46: 1056 - 1062

[19] Kim GH, Cho YK, Kim EY et al. Comparison of 22-gauge aspiration needle with 22-gauge biopsy needle in endoscopic ultrasonographyguided subepithelial tumor sampling. Scand J Gastroenterol 2014; 49: $347-354$

[20] Hucl T, Wee E, Anuradha S et al. Feasibility and efficiency of a new 22G core needle: a prospective comparison study. Endoscopy 2013; 45: $792-798$

[21] Bang JY, Hebert-Magee S, Trevino J et al. Randomized trial comparing the 22-gauge aspiration and 22-gauge biopsy needles for EUS-guided sampling of solid pancreatic mass lesions. Gastrointest Endosc 2012; 76: $321-327$

[22] DeWitt J, Cho CM, Lin J et al. Comparison of EUS-guided tissue acquisition using two different 19-gauge core biopsy needles: a multicenter, prospective, randomized, and blinded study. Endosc Int Open 2015; 3: E471-E478

[23] Ang TL, Kwek AB, Seo DW et al. A prospective randomized study of the difference in diagnostic yield between endoscopic ultrasound-guided fine-needle aspiration (EUSFNA) needles with and without a side port in pancreatic masses. Endosc Int Open 2015; 3: E329-E333

[24] Carrara S, Anderloni A, Jovani M et al. A prospective randomized study comparing 25-G and 22-G needles of a new platform for endoscopic ultrasound-guided fine needle aspiration of solid masses. Dig Liver Dis 2016; 48: $49-54$

[25] Gimeno-Garcia AZ, Elwassief A, Paquin SC et al. Randomized controlled trial comparing stylet-free endoscopic ultrasound-guided fine-needle aspiration with 22-G and 25-G needles. Dig Endosc 2014; 26: $467-473$

[26] Lee JK, Lee KT, Choi ER et al. A prospective, randomized trial comparing 25-gauge and 22-gauge needles for endoscopic ultrasound-guided fine needle aspiration of pancreatic masses. Scand J Gastroenterol 2013; 48: $752-757$

[27] Vilmann P, Saftoiu A, Hollerbach S et al. Multicenter randomized controlled trial comparing the performance of 22 gauge versus 25 gauge EUS-FNA needles in solid masses. Scand J Gastroenterol 2013; 48: $877-883$ 
[28] Camellini L, Carlinfante G, Azzolini F et al. A randomized clinical trial comparing $22 \mathrm{G}$ and $25 \mathrm{G}$ needles in endoscopic ultrasound-guided fine-needle aspiration of solid lesions. Endoscopy 2011; 43: 709- 715

[29] Fabbri C, Polifemo AM, Luigiano C et al. Endoscopic ultrasound-guided fine needle aspiration with 22- and 25-gauge needles in solid pancreatic masses: a prospective comparative study with randomisation of needle sequence. Dig Liver Dis 2011; 43: 647-652

[30] Siddiqui UD, Rossi F, Rosenthal LS et al. EUS-guided FNA of solid pancreatic masses: a prospective, randomized trial comparing 22-gauge and 25-gauge needles. Gastrointest Endosc 2009; 70: 1093-1097

[31] Lee JH, Stewart J, Ross WA et al. Blinded prospective comparison of the performance of 22-gauge and 25-gauge needles in endoscopic ultrasound-guided fine needle aspiration of the pancreas and peripancreatic lesions. Dig Dis Sci 2009; 54: 2274-2281

[32] Park SW, Chung M], Lee SH et al. Prospective study for comparison of endoscopic ultrasound-guided tissue acquisition using 25- and 22gauge core biopsy needles in solid pancreatic masses. PLoS One 2016; 11: e0154401

[33] Song TJ, Kim JH, Lee SS et al. The prospective randomized, controlled trial of endoscopic ultrasound-guided fine-needle aspiration using $22 \mathrm{G}$ and $19 \mathrm{G}$ aspiration needles for solid pancreatic or peripancreatic masses. Am J Gastroenterol 2010; 105: 1739-1745

[34] Tarantino I, Di Mitri R, Fabbri C et al. Is diagnostic accuracy of fine needle aspiration on solid pancreatic lesions aspiration-related? A multicentre randomised trial Dig Liver Dis 2014; 46: 523-526

[35] Lee JK, Choi JH, Lee KH et al. A prospective, comparative trial to optimize sampling techniques in EUS-guided FNA of solid pancreatic masses. Gastrointest Endosc 2013; 77: 745 - 751

[36] Puri R, Vilmann P, Saftoiu A et al. Randomized controlled trial of endoscopic ultrasound-guided fine-needle sampling with or without suction for better cytological diagnosis. Scand J Gastroenterol 2009; 44: $499-504$

[37] Wallace MB, Kennedy T, Durkalski V et al. Randomized controlled trial of EUS-guided fine needle aspiration techniques for the detection of malignant lymphadenopathy. Gastrointest Endosc 2001; 54: 441 447

[38] Kudo T, Kawakami H, Hayashi T et al. High and low negative pressure suction techniques in EUS-guided fine-needle tissue acquisition by using 25-gauge needles: a multicenter, prospective, randomized, controlled trial. Gastrointest Endosc 2014; 80: 1030 - 1037 e1

[39] Attam R, Arain MA, Bloechl S] et al. "Wet suction technique (WEST)": a novel way to enhance the quality of EUS-FNA aspirate. Results of a prospective, single-blind, randomized, controlled trial using a 22gauge needle for EUS-FNA of solid lesions. Gastrointest Endosc 2015; 81: $1401-1407$

[40] Aadam AA, Oh YS, Shidham VB et al. Eliminating the residual negative pressure in the endoscopic ultrasound aspirating needle enhances cytology yield of pancreas masses. Dig Dis Sci 2016; 61: 890 - 899

[41] Abe Y, Kawakami H, Oba K et al. Effect of a stylet on a histological specimen in EUS-guided fine-needle tissue acquisition by using 22gauge needles: a multicenter, prospective, randomized, controlled trial. Gastrointest Endosc 2015; 82: 837-844 e1

[42] Nijhawan S, Singh B, Kumar A et al. Randomized controlled trial of comparison of the adequacy, and diagnostic yield of endoscopic ultrasound guided fine needle aspiration with and without a stylet in Indian patients: A prospective single blind study. J Dig Endosc 2014; 5: $149-153$

[43] Wani S, Early D, Kunkel J et al. Diagnostic yield of malignancy during EUS-guided FNA of solid lesions with and without a stylet: a prospective, single blind, randomized, controlled trial. Gastrointest Endosc 2012; 76: $328-335$

[44] Rastogi A, Wani S, Gupta N et al. A prospective, single-blind, randomized, controlled trial of EUS-guided FNA with and without a stylet. Gastrointest Endosc 2011; 74: 58 - 64
[45] Sugimoto M, Takagi T, Hikichi T et al. Conventional versus contrastenhanced harmonic endoscopic ultrasonography-guided fine-needle aspiration for diagnosis of solid pancreatic lesions: A prospective randomized trial. Pancreatology 2015; 15: 538-541

[46] Bang JY, Magee SH, Ramesh J et al. Randomized trial comparing fanning with standard technique for endoscopic ultrasound-guided fineneedle aspiration of solid pancreatic mass lesions. Endoscopy 2013; 45: $445-450$

[47] Wani S, Mullady D, Early DS et al. The clinical impact of immediate onsite cytopathology evaluation during endoscopic ultrasound-guided fine needle aspiration of pancreatic masses: a prospective multicenter randomized controlled trial. Am J Gastroenterol 2015; 110: 14291439

[48] Lee LS, Nieto J, Watson RR et al. Randomized noninferiority trial comparing diagnostic yield of cytopathologist-guided versus 7 passes for EUS-FNA of pancreatic masses. Dig Endosc 2015; 28: 469-475

[49] Lee JK, Choi ER, Jang TH et al. A prospective comparison of liquidbased cytology and traditional smear cytology in pancreatic endoscopic ultrasound-guided fine needle aspiration. Acta Cytol 2011; 55 : $401-407$

[50] Bang JY, Hawes R, Varadarajulu S. A meta-analysis comparing ProCore and standard fine-needle aspiration needles for endoscopic ultrasound-guided tissue acquisition. Endoscopy 2016; 48: 339-349

[51] Oh HC, Kang H, Lee JY et al. Diagnostic accuracy of 22/25-gauge core needle in endoscopic ultrasound-guided sampling: systematic review and meta-analysis. Korean J Intern Med 2016; 31: 1073-1083

[52] Facciorusso A, Stasi E, Di Maso M et al. Endoscopic ultrasound-guided fine needle aspiration of pancreatic lesions with 22 versus 25 gauge needles: A meta-analysis. United European Gastroenterol J 2016: (Epub ahead of print) doi:10.1177/2050640616680972

[53] Xu MM, Jia HY, Yan LL et al. Comparison of two different size needles in endoscopic ultrasound-guided fine-needle aspiration for diagnosing solid pancreatic lesions: a meta-analysis of prospective controlled trials. Medicine (Baltimore) 2017; 96: e5802

[54] Madhoun MF, Wani SB, Rastogi A et al. The diagnostic accuracy of 22 gauge and 25-gauge needles in endoscopic ultrasound-guided fine needle aspiration of solid pancreatic lesions: a meta-analysis. Endoscopy 2013; 45: 86 - 92

[55] Affolter KE, Schmidt RL, Matynia AP et al. Needle size has only a limited effect on outcomes in EUS-guided fine needle aspiration: a systematic review and meta-analysis. Dig Dis Sci 2013; 58: 1026-1034

[56] Kim JH, Park SW, Kim MK et al. Meta-analysis for cyto-pathological outcomes in endoscopic ultrasonography-guided fine-needle aspiration with and without the stylet. Dig Dis Sci 2016; 61: 2175-2184

[57] Hebert-Magee S, Bae S, Varadarajulu $S$ et al. The presence of a cytopathologist increases the diagnostic accuracy of endoscopic ultrasound-guided fine needle aspiration cytology for pancreatic adenocarcinoma: a meta-analysis. Cytopathology 2013; 24: 159-171

[58] Matynia AP, Schmidt RL, Barraza G et al. Impact of rapid on-site evaluation on the adequacy of endoscopic-ultrasound guided fine-needle aspiration of solid pancreatic lesions: a systematic review and metaanalysis. J Gastroenterol Hepatol 2014; 29: 697-705

[59] Kong F, Zhu J, Kong $X$ et al. Rapid on-site evaluation does not improve endoscopic ultrasound-guided fine needle aspiration adequacy in pancreatic masses: a meta-analysis and systematic review. PLoS One 2016; 11: e0163056

[60] Hewitt M], McPhail M], Possamai L et al. EUS-guided FNA for diagnosis of solid pancreatic neoplasms: a meta-analysis. Gastrointest Endosc 2012; 75: 319-331

[61] Gopalakrishna G, Mustafa RA, Davenport C et al. Applying Grading of Recommendations Assessment, Development and Evaluation (GRADE) to diagnostic tests was challenging but doable. J Clin Epidemiol 2014; 67: 760 - 768 
[62] Mounzer R, Yen R, Marshall C et al. Interobserver agreement among cytopathologists in the evaluation of pancreatic endoscopic ultrasound-guided fine needle aspiration cytology specimens. Endosc Int Open 2016; 4: E812-E819

[63] Adler DG, Witt B, Chadwick B et al. Pathologic evaluation of a new endoscopic ultrasound needle designed to obtain core tissue samples: A pilot study. Endosc Ultrasound 2016; 5: $178-183$

[64] Kandel P, Tranesh G, Nassar A et al. EUS-guided fine needle biopsy sampling using a novel fork-tip needle: a case-control study. Gastrointest Endosc 2016; 84: 1034 - 1039

[65] DiMaio CJ, Kolb JM, Benias PC et al. Initial experience with a novel EUSguided core biopsy needle (SharkCore): results of a large North American multicenter study. Endosc Int Open 2016; 4: E974 - E979

[66] Bang JY, Hebert-Magee S, Hasan MK et al. Endoscopic ultrasonography-guided biopsy using a Franseen needle design: Initial assessment. Dig Endosc 2017; 29: 338 - 346

[67] Nayar MK, Paranandi B, Dawwas MF et al. Comparison of the diagnostic performance of 2 core biopsy needles for EUS-guided tissue acquisition from solid pancreatic lesions. Gastrointest Endosc 2017; 85: $1017-1024$

[68] Jovani M, Abidi WM, Lee LS. Novel fork-tip needles versus standard needles for EUS-guided tissue acquisition from solid masses of the upper GI tract: a matched cohort study. Scand J Gastroenterol 2017; 52: $784-787$

[69] El Chafic AH, Loren D, Siddiqui A et al. Comparison of FNA and fineneedle biopsy for EUS-guided sampling of suspected GI stromal tumors. Gastrointest Endosc 2017; 86: 510-515

[70] Rodrigues-Pinto E, Jalaj S, Grimm IS et al. Impact of EUS-guided fineneedle biopsy sampling with a new core needle on the need for onsite cytopathologic assessment: a preliminary study. Gastrointest Endosc 2016; 84: 1040 - 1046

[71] Schulman AR, Thompson CC, Odze R et al. Optimizing EUS-guided liver biopsy sampling: comprehensive assessment of needle types and tissue acquisition techniques. Gastrointest Endosc 2017; 85: 419426

[72] Nakai Y, Isayama H, Chang KJ et al. A pilot study of EUS-guided through-the-needle forceps biopsy (with video). Gastrointest Endosc 2016; 84: $158-162$

[73] Yusuf TE, Ho S, Pavey DA et al. Retrospective analysis of the utility of endoscopic ultrasound-guided fine-needle aspiration (EUS-FNA) in pancreatic masses, using a 22-gauge or 25-gauge needle system: a multicenter experience. Endoscopy 2009; 41: 445-448

[74] Itoi T, Itokawa F, Kurihara T et al. Experimental endoscopy: objective evaluation of EUS needles. Gastrointest Endosc 2009; 69: 509-516

[75] Itoi T, Itokawa F, Sofuni A et al. Evaluation of 19-gauge endoscopic ultrasonography aspiration needles using various echoendoscopes. Endosc Int Open 2013; 1: 24-30

[76] Varadarajulu S, Bang JY, Hebert-Magee S. Assessment of the technical performance of the flexible 19-gauge EUS-FNA needle. Gastrointest Endosc 2012; 76: 336-343

[77] Songur N, Songur Y, Bircan S et al. Comparison of 19- and 22-gauge needles in EUS-guided fine needle aspiration in patients with mediastinal masses and lymph nodes. Turk J Gastroenterol 2011; 22: 472 478

[78] Ramesh J, Bang JY, Hebert-Magee S et al. Randomized trial comparing the flexible 19G and 25G needles for endoscopic ultrasound-guided fine needle aspiration of solid pancreatic mass lesions. Pancreas 2015; 44: $128-133$

[79] Retraction. Randomized trial comparing the flexible $19 \mathrm{G}$ and $25 \mathrm{C}$ needles for endoscopic ultrasound-guided fine needle aspiration of solid pancreatic mass lesions. Pancreas 2016; 45: 160
[80] Larghi A, Verna EC, Ricci R et al. EUS-guided fine-needle tissue acquisition by using a 19-gauge needle in a selected patient population: a prospective study. Gastrointest Endosc 2011; 74: $504-510$

[81] Iglesias-Garcia J, Abdulkader I, Larino-Noia J et al. Evaluation of the adequacy and diagnostic accuracy of the histology samples obtained with a newly designed 19-gauge EUS histology needle. Rev Esp Enferm Dig 2014; 106: 6-14

[82] Iwashita T, Yasuda I, Mukai T et al. Macroscopic on-site quality evaluation of biopsy specimens to improve the diagnostic accuracy during EUS-guided FNA using a 19-gauge needle for solid lesions: a singlecenter prospective pilot study (MOSE study). Gastrointest Endosc 2015; 81: $177-185$

[83] Iglesias-Garcia J, Poley JW, Larghi A et al. Feasibility and yield of a new EUS histology needle: results from a multicenter, pooled, cohort study. Gastrointest Endosc 2011; 73: 1189-1196

[84] Yasuda I, Tsurumi H, Omar S et al. Endoscopic ultrasound-guided fineneedle aspiration biopsy for lymphadenopathy of unknown origin. Endoscopy 2006; 38: 919-924

[85] Larghi A, Fuccio L, Chiarello G et al. Fine-needle tissue acquisition from subepithelial lesions using a forward-viewing linear echoendoscope. Endoscopy 2014; 46: 39-45

[86] Larghi A, Iglesias-Garcia J, Poley JW et al. Feasibility and yield of a novel 22-gauge histology EUS needle in patients with pancreatic masses: a multicenter prospective cohort study. Surg Endosc 2013; 27: $3733-3738$

[87] Paik WH, Park Y, Park do $\mathrm{H}$ et al. Prospective evaluation of new 22 gauge endoscopic ultrasound core needle using capillary sampling with stylet slow-pull technique for intra-abdominal solid masses. J Clin Gastroenterol 2015; 49: 199-205

[88] Iwashita T, Nakai Y, Samarasena JB et al. High single-pass diagnostic yield of a new 25-gauge core biopsy needle for EUS-guided FNA biopsy in solid pancreatic lesions. Gastrointest Endosc 2013; 77: 909-915

[89] Fabbri C, Luigiano C, Maimone A et al. Endoscopic ultrasound-guided fine-needle biopsy of small solid pancreatic lesions using a 22-gauge needle with side fenestration. Surg Endosc 2015; 29: 1586 - 1590

[90] Jenssen C, Hocke M, Fusaroli P et al. EFSUMB guidelines on interventional ultrasound (INVUS), Part IV - EUS-guided interventions: General aspects and EUS-guided sampling (long version). Ultraschall Med 2016; 37: E33-E76

[91] Villa NA, Berzosa M, Wallace MB et al. Endoscopic ultrasound-guided fine needle aspiration: The wet suction technique. Endosc Ultrasound 2016; 5: $17-20$

[92] Katanuma A, Itoi T, Baron TH et al. Bench-top testing of suction forces generated through endoscopic ultrasound-guided aspiration needles. J Hepatobiliary Pancreat Sci 2015; 22: 379-385

[93] Chen JY, Ding QY, Lv Y et al. Slow-pull and different conventional suction techniques in endoscopic ultrasound-guided fine-needle aspiration of pancreatic solid lesions using 22-gauge needles. World J Gastroenterol 2016; 22: 8790 -8797

[94] Nakai Y, Isayama H, Chang KJ et al. Slow pull versus suction in endoscopic ultrasound-guided fine-needle aspiration of pancreatic solid masses. Dig Dis Sci 2014; 59: 1578-1585

[95] Kin T, Katanuma A, Yane K et al. Diagnostic ability of EUS-FNA for pancreatic solid lesions with conventional 22-gauge needle using the slow pull technique: a prospective study. Scand J Gastroenterol 2015; 50: $900-907$

[96] Saxena P, El Zein M, Stevens T et al. A randomized multicenter trial comparing capillary suction and standard suction for endoscopic ultrasound-guided fine needle aspiration (EUS-FNA) of solid pancreatic lesions. Gastrointest Endosc 2015; 81: AB539 
[97] Yamabe A, Irisawa A, Shibukawa G et al. An experimental study to assess the best maneuver when using a reverse side-bevel histology needle for EUS-guided fine-needle biopsy. Endosc Int Open 2016; 4: E56-E61

[98] El Haddad R, Barret M, Beuvon F et al. The slow-pull capillary technique increases the quality of endoscopic ultrasound fine needle biopsy samples in solid pancreatic lesions. Eur J Gastroenterol Hepatol 2016; 28: $911-916$

[99] Sahai AV, Paquin SC, Gariepy G. A prospective comparison of endoscopic ultrasound-guided fine needle aspiration results obtained in the same lesion, with and without the needle stylet. Endoscopy 2010; 42: $900-903$

[100] Wani S, Gupta N, Gaddam S et al. A comparative study of endoscopic ultrasound guided fine needle aspiration with and without a stylet. Dig Dis Sci 2011; 56: 2409-2414

[101] Gimeno-Garcia AZ, Paquin SC, Gariepy G et al. Comparison of endoscopic ultrasonography-guided fine-needle aspiration cytology results with and without the stylet in 3364 cases. Dig Endosc 2013; 25: 303-307

[102] Seicean A, Badea R, Moldovan-Pop A et al. Harmonic contrast-enhanced endoscopic ultrasonography for the guidance of fine-needle aspiration in solid pancreatic masses. Ultraschall Med 2017; 38: $174-182$

[103] Hou X, Jin Z, Xu C et al. Contrast-enhanced harmonic endoscopic ultrasound-guided fine-needle aspiration in the diagnosis of solid pancreatic lesions: a retrospective study. PLoS One 2015; 10: e0121236

[104] Mohamadnejad M, Mullady D, Early DS et al. Increasing number of passes beyond 4 does not increase sensitivity of detection of pancreatic malignancy by endoscopic ultrasound-guided fine-needle aspiration. Clin Gastroenterol Hepatol 2017; 15: 1071 -1078 e2

[105] van Riet PA, Cahen DL, Poley JW et al. Mapping international practice patterns in EUS-guided tissue sampling: outcome of a global survey. Endosc Int Open 2016; 4: E360 - E370

[106] Nguyen YP, Maple JT, Zhang Q et al. Reliability of gross visual assessment of specimen adequacy during EUS-guided FNA of pancreatic masses. Gastrointest Endosc 2009; 69: 1264 - 1270

[107] Al-Haddad MA, Kowalski T, Siddiqui A et al. Integrated molecular pathology accurately determines the malignant potential of pancreatic cysts. Endoscopy 2015; 47: 136-142

[108] Khalid A, Zahid M, Finkelstein SD et al. Pancreatic cyst fluid DNA analysis in evaluating pancreatic cysts: a report of the PANDA study. Gastrointest Endosc 2009; 69: 1095-102

[109] Thornton GD, McPhail MJ, Nayagam S et al. Endoscopic ultrasound guided fine needle aspiration for the diagnosis of pancreatic cystic neoplasms: a meta-analysis. Pancreatology 2013; 13: 48 - 57

[110] Wang QX, Xiao J, Orange M et al. EUS-guided FNA for diagnosis of pancreatic cystic lesions: a meta-analysis. Cell Physiol Biochem 2015; 36: $1197-1209$

[111] Zhu H, Jiang F, Zhu J et al. Assessment of morbidity and mortality associated with endoscopic ultrasound-guided fine-needle aspiration for pancreatic cystic lesions: a systematic review and meta-analysis. Dig Endosc 2017: (Epub ahead of print) doi:10.1111/ den.12851

[112] Barresi L, Tarantino I, Traina M et al. Endoscopic ultrasound-guided fine needle aspiration and biopsy using a 22-gauge needle with side fenestration in pancreatic cystic lesions. Dig Liver Dis 2014; 46: 45 50

[113] Hong SK, Loren DE, Rogart JN et al. Targeted cyst wall puncture and aspiration during EUS-FNA increases the diagnostic yield of premalignant and malignant pancreatic cysts. Gastrointest Endosc 2012; 75: $775-782$
[114] Lim LG, Lakhtakia S, Ang TL et al. Factors determining diagnostic yield of endoscopic ultrasound guided fine-needle aspiration for pancreatic cystic lesions: a multicentre Asian study. Dig Dis Sci 2013; 58: $1751-1757$

[115] Rogart JN, Loren DE, Singu BS et al. Cyst wall puncture and aspiration during EUS-guided fine needle aspiration may increase the diagnostic yield of mucinous cysts of the pancreas. J Clin Gastroenterol 2011; 45: $164-169$

[116] Attili F, Pagliari D, Rimbas M et al. Endoscopic ultrasound-guided histological diagnosis of a mucinous non-neoplastic pancreatic cyst using a specially designed through-the-needle microforceps. Endoscopy 2016; 48 : E188-E189

[117] Pham KD, Engjom T, Gjelberg Kollesete $\mathrm{H}$ et al. Diagnosis of a mucinous pancreatic cyst and resection of an intracystic nodule using a novel through-the-needle micro forceps. Endoscopy 2016; 48: E125-E126

[118] Veitch AM, Vanbiervliet G, Gershlick AH et al. Endoscopy in patients on antiplatelet or anticoagulant therapy, including direct oral anticoagulants: British Society of Gastroenterology (BSG) and European Society of Gastrointestinal Endoscopy (ESGE) guidelines. Endoscopy 2016; 48: 385-402

[119] Wang KX, Ben QW, Jin ZD et al. Assessment of morbidity and mortality associated with EUS-guided FNA: a systematic review. Gastrointest Endosc 2011; 73: 283-290

[120] Banafea O, Mghanga FP, Zhao J et al. Endoscopic ultrasonography with fine-needle aspiration for histological diagnosis of solid pancreatic masses: a meta-analysis of diagnostic accuracy studies. BMC Gastroenterol 2016; 16: 108

[121] Levy M], Abu Dayyeh BK, Fujii LL et al. Prospective evaluation of adverse events following lower gastrointestinal tract EUS FNA. Am J Gastroenterol 2014; 109: 676-685

[122] Guarner-Argente C, Shah P, Buchner A et al. Use of antimicrobials for EUS-guided FNA of pancreatic cysts: a retrospective, comparative analysis. Gastrointest Endosc 2011; 74: 81-86

[123] Klein A, Qi R, Nagubandi S et al. Single-dose intra-procedural ceftriaxone during endoscopic ultrasound fine-needle aspiration of pancreatic cysts is safe and effective: results from a single tertiary center. Ann Gastroenterol 2017; 30: 237-241

[124] Marinos E, Lee S, Jones B et al. Outcomes of single-dose peri-procedural antibiotic prophylaxis for endoscopic ultrasound-guided fineneedle aspiration of pancreatic cystic lesions. United European Gastroenterol J 2014; 2: $391-396$

[125] Qin SY, Zhou Y, Li P et al. Diagnostic efficacy of cell block immunohistochemistry, smear cytology, and liquid-based cytology in endoscopic ultrasound-guided fine-needle aspiration of pancreatic lesions: a single-institution experience. PLoS One 2014; 9: e108762

[126] Weynand B, Borbath I, Galant C et al. Optimizing specimen collection and laboratory procedures reduces the non-diagnostic rate for endoscopic ultrasound-guided fine-needle aspiration of solid lesions of the pancreas. Cytopathology 2013; 24: 177-184

[127] Kopelman Y, Marmor S, Ashkenazi I et al. Value of EUS-FNA cytological preparations compared with cell block sections in the diagnosis of pancreatic solid tumours. Cytopathology 2011; 22: 174-178

[128] LeBlanc JK, Emerson RE, Dewitt J et al. A prospective study comparing rapid assessment of smears and ThinPrep for endoscopic ultrasound-guided fine-needle aspirates. Endoscopy 2010; 42: 389-394

[129] Ardengh JC, Lopes CV, de Lima LF et al. Cell block technique and cytological smears for the differential diagnosis of pancreatic neoplasms after endosonography-guided fine-needle aspiration. Acta Gastroenterol Latinoam 2008; 38: 246-251

[130] de Luna R, Eloubeidi MA, Sheffield MV et al. Comparison of ThinPrep and conventional preparations in pancreatic fine-needle aspiration biopsy. Diagn Cytopathol 2004; 30: 71-76 
[131] Kim JH, Lee S], Moon SH et al. Incremental value of cell block preparations over conventional smears alone in the evaluation of EUSFNA for pancreatic masses. Hepatogastroenterology 2014; 61: $2117-2122$

[132] Haba S, Yamao K, Bhatia V et al. Diagnostic ability and factors affecting accuracy of endoscopic ultrasound-guided fine needle aspiration for pancreatic solid lesions: Japanese large single center experience. J Gastroenterol 2013; 48: 973-981

[133] Rong L, Kida M, Yamauchi $\mathrm{H}$ et al. Factors affecting the diagnostic accuracy of endoscopic ultrasonography-guided fine-needle aspira- tion (EUS-FNA) for upper gastrointestinal submucosal or extraluminal solid mass lesions. Dig Endosc 2012; 24: 358 - 363

[134] Moller K, Papanikolaou IS, Toermer T et al. EUS-guided FNA of solid pancreatic masses: high yield of 2 passes with combined histologiccytologic analysis. Gastrointest Endosc 2009; 70: 60-99

[135] Noda Y, Fujita N, Kobayashi G et al. Diagnostic efficacy of the cell block method in comparison with smear cytology of tissue samples obtained by endoscopic ultrasound-guided fine-needle aspiration. J Gastroenterol 2010; 45: 868-875 